\title{
Correction to: Characterization of the Cerebrospinal Fluid Proteome in Patients with Fragile X-Associated Tremor/Ataxia Syndrome
}

\author{
Diana A. Abbasi ${ }^{1} \cdot$ Thu T. A. Nguyen ${ }^{2}$ • Deborah A. Hall ${ }^{3}$ Erin Robertson-Dick ${ }^{4}$ Elizabeth Berry-Kravis ${ }^{1}$. \\ Stephanie M. Cologna ${ }^{2,5}$
}

Published online: 10 September 2021

๑) Springer Science+Business Media, LLC, part of Springer Nature 2021

\section{Correction to: The Cerebellum \\ https://doi.org/10.1007/s12311-021-01262-7}

The original version of this article duplicated figures. In the published version of this article, Figures 2 and 3 are identical. With this, the correct figures are published.

The original article was corrected.

The original article can be found online at https://doi.org/10.1007/ s12311-021-01262-7.

Stephanie M. Cologna

cologna@uic.edu

1 Department of Pediatrics and Neurological Sciences, Rush University Medical Center, Chicago, IL, USA

2 Department of Chemistry, University of Illinois At Chicago, Chicago, IL, USA

3 Department of Neurological Sciences, Rush University Medical Center, Chicago, IL, USA

4 Department of Communication Sciences and Disorders, Northwestern University, Chicago, IL, USA

5 Laboratory of Integrated Neuroscience, University of Illinois At Chicago, 845 W Taylor Street, Room 4500, Chicago, IL 60607, USA 


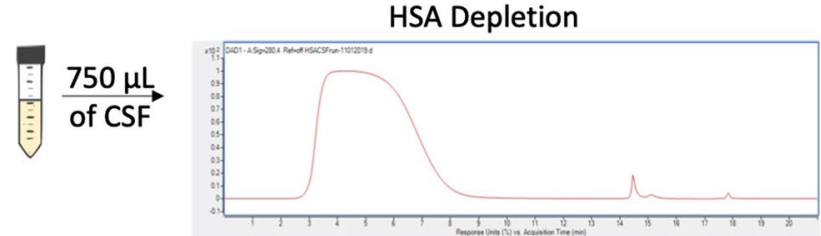

50 ug for each sample

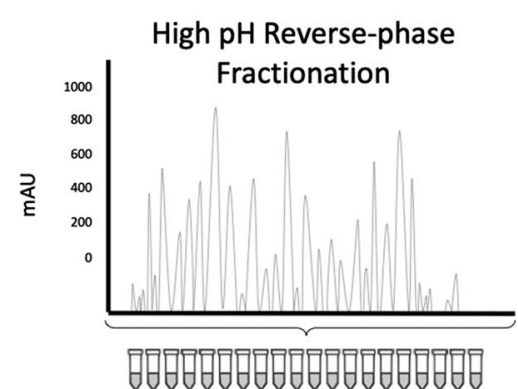

Reduction, alkylation,

and in-solution digest

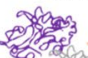

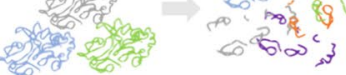

ITRAQ Labeling

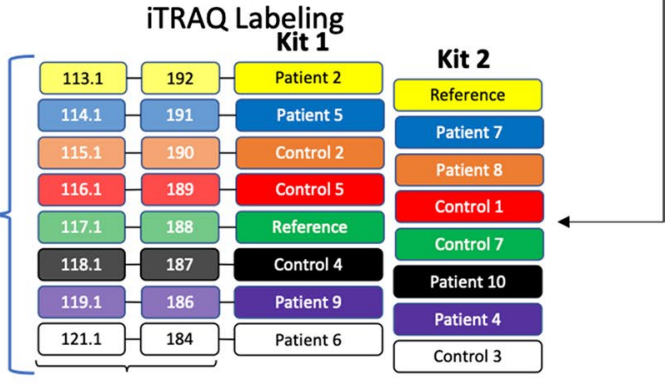

Total Mass: 305.1

Nano-LC-MS/MS

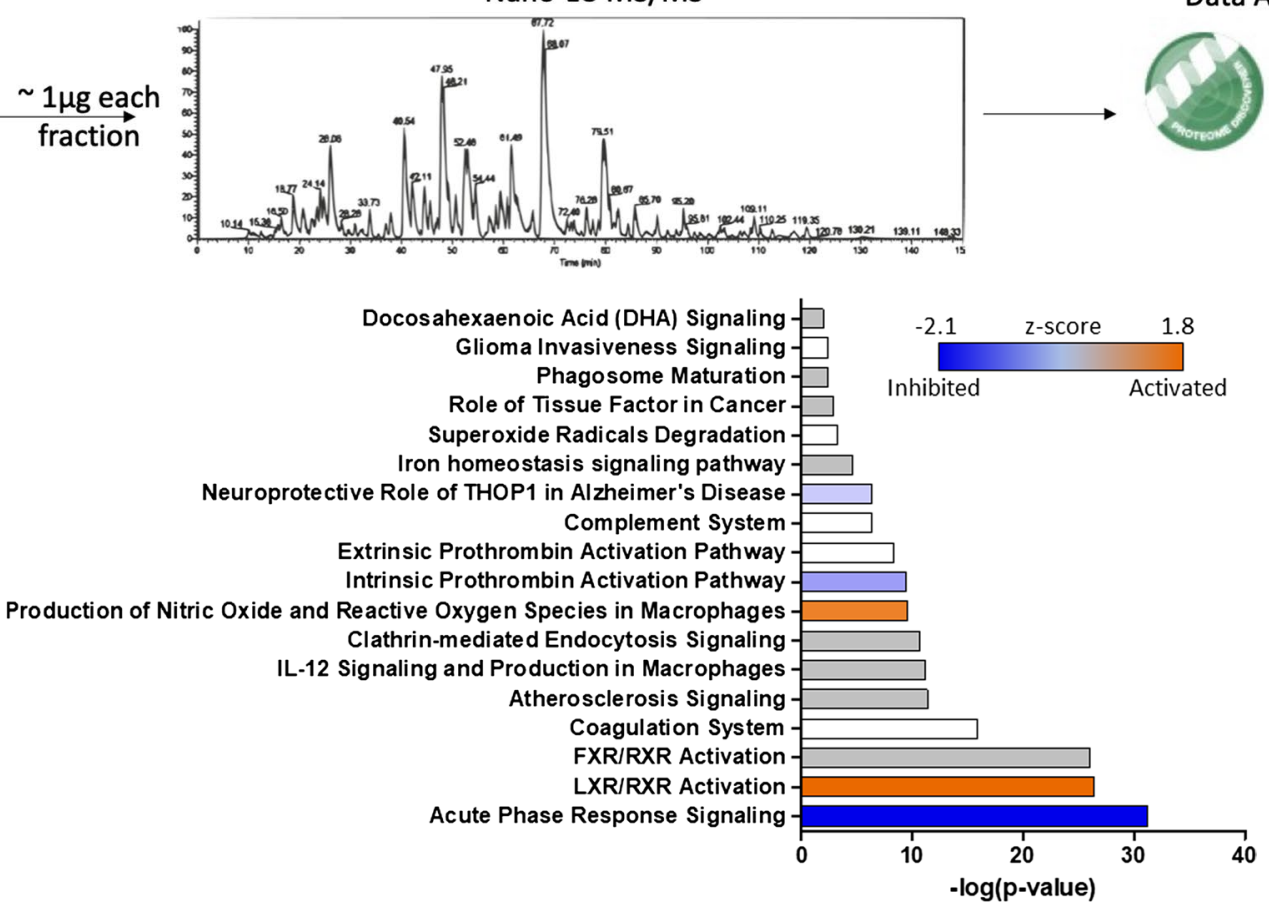

Publisher's Note Springer Nature remains neutral with regard to jurisdictional claims in published maps and institutional affiliations. 